\title{
Inhibitory Effect of AL-3264, a New Antiallergic Agent, on the Prausnitz-Küstner Reaction and Leukotriene Production in Monkeys
}

\author{
Ikuhisa Yakuo', Katsumi Ishii ${ }^{1}$, Chikako Sakaki ${ }^{1}$, Hideo Nakamura ${ }^{2}$ and Kunihiko Takeyama' \\ 'Department of Pharmacology, Exploratory Research Laboratories, ${ }^{2}$ Department of Drug Regulatory Affairs, Dainippon Pharmaceutical Co., Ltd., \\ Enoki 33-94, Suita, Osaka 564, Japan
}

Received October 28, 1994 Accepted January 12, 1995

\begin{abstract}
To clarify the antiallergic effect and antiallergic mechanism of AL-3264 ( $N$-[4-[4-(diphenylmethy])1-piperazinyl]butyl]-3-(6-methyl-3-pyridyl)acrylamide) in monkeys, its effects on the Prausnitz-Küstner (P$\mathrm{K})$ reaction, the histamine skin reaction and leukotriene production were examined. In contrast to ketotifen and mepyramine, AL-3264 inhibited the P-K reaction, which is mainly mediated by leukotriene and histamine, more clearly than the skin reaction evoked by histamine alone. AL-3264 also inhibited the leukotriene (LT) production in the broncho-alveolar cells, suggesting that the inhibition of LT production actually contributes to the antiallergic effect of AL-3264.
\end{abstract}

Keywords: AL-3264, Prausnitz-Küstner reaction, Monkey

$N$ - [4- [4-(Diphenylmethyl) - 1 - piperazinyl] butyl] -3-(6methyl-3-pyridyl)acrylamide (AL-3264) is a new antiallergic agent that possesses a 5-lipoxygenase (5-LO) inhibiting property together with the abilities to block histamine $\mathrm{H}_{1}$-receptors and inhibit histamine release (1), but has very little sedative effect (2). The metabolism of AL-3264 in humans has also been assessed to be similar to that in monkeys, but not in rats.

The monkey is thought to be a good experimental animal in which to develop allergic reactions, i.e., asthma, cedar pollinosis and the Prausnitz-Küstner (P-K) reaction $(3-5)$, because its mast cells and basophils can be passively sensitized with human IgE antibody $(6,7)$. We recently revealed that the $P-K$ reaction in monkeys is mediated by leukotriene (LT) and histamine, similar to the mediation of human allergic diseases, and proposed that it is useful for the evaluation of antiallergic drugs (unpublished data, I. Yakuo and H. Nakamura).

Some antiallergic drugs with multiple mechanisms of action have been developed, but these in vivo mechanisms of action have hardly been compared at the same time and at the effective dose. To assess the antiallergic effect and antiallergic mechanism of AL-3264 in monkeys, the effect of AL-3264 on the P-K reaction was compared with that on the histamine skin reaction in the same monkeys.

Furthermore, its effect on LT production was examined using the broncho-alveolar cells of monkeys pretreated with AL-3264. Broncho-alveolar lavage is a useful method for the collection of proinflammatory cells and for the diagnosis or treatment of respiratory diseases. The method that is generally used in clinical studies is applied to experimental animals such as monkeys.

Young adult cynomolgus monkeys (Japan SLC, Inc., Hamamatsu) were used for the experiments at an interval of more than a month. The P-K reaction was performed as follows: Forearm skin sites of monkeys (female, $2.5-4 \mathrm{~kg}$ ) were sensitized with an intradermal injection ( $20 \mu \mathrm{l} / \mathrm{site}$ ) of 5 times-diluted serum from an asthmatic patient. Two days later, the monkeys were challenged with dust mite antigen extract by an intradermal injection $(0.2 \mu \mathrm{g} / 20 \mu \mathrm{l} / \mathrm{site})$ into the 6 sensitized skin sites. In the same monkeys, the histamine skin reaction was also induced by an intradermal injection of histamine solution $(0.2 \mu \mathrm{g} / 20 \mu \mathrm{l} / \mathrm{site})$ into 5 unsensitized forearm skin sites. After 20 min (antigen injection) or $10 \mathrm{~min}$ (histamine injection), the wheal diameters at the dermal injection sites were measured by dial calipers, and the wheal size was expressed as the product $\left(\mathrm{mm}^{2}\right)$ of the longest diameter and the line perpendicular to it. To eliminate non-specific skin reactions, the size of blank wheals, which were induced by an intradermal injection of dust mite extract or saline into unsensitized skin sites, was subtracted from each wheal size. The $\mathbf{P}-\mathrm{K}$ reaction and the histamine skin reaction were induced in each monkey before and at 1 and 3 $\mathrm{hr}$ after the oral administration of test drugs. The inhibitory rate $(\%)$ was calculated from the pre-drug value and 
the value at 1 or $3 \mathrm{hr}$ after the drug administration.

The ex vivo study of $\mathbf{L T}$ production was performed as follows: AL-3264 $(5 \mathrm{mg} / \mathrm{kg})$ or vehicle $(0.5 \%$ tragacanth solution) was orally administered to 5 monkeys (male, 4-6 kg), and the opposite treatment was carried out in each monkey after a month. One hour after the administration, a pediatric fiberoptic bronchoscope with a cannula (BF-P20 type; Olympus, Tokyo) was introduced into the third bronchi of the right lung lobe under anesthesia with ketamine $(10 \mathrm{mg} / \mathrm{kg}, \mathrm{i} . \mathrm{m}$.). Saline $(10 \mathrm{ml})$ warmed at $37 \mathrm{C}$ was instilled into the lobe through the cannula using a syringe and then aspirated gently to collect the bronchoalveolar lavage fluids (BALF). This procedure was repeated 3 times, and the 2nd and 3rd BALF were used for the experiment. Exudated cells in the BALF were centrifuged at $1540 \mathrm{rpm}$ at $4{ }^{\circ} \mathrm{C}$ for $10 \mathrm{~min}$, washed with $\mathrm{Ca}^{2+}$-free Tyrode solution 2 times, and resuspended into Tyrode solution at a density of $10^{5}$ cells $/ \mathrm{ml}$. More than $80 \%$ of the cells were confirmed to be macrophages by Giemza staining. The cell suspension was incubated with ionophore A23, $187(0.5 \mu \mathrm{M})$ at $37^{\circ} \mathrm{C}$ for $15 \mathrm{~min}$ and then centrifuged at $2,000 \mathrm{rpm}$ at $4^{\circ} \mathrm{C}$ for $10 \mathrm{~min}$. The level of $\mathrm{LTB}_{4}$ in the supernatant was measured by RIA.

The following drugs and agents were used: histamine di-
(A)

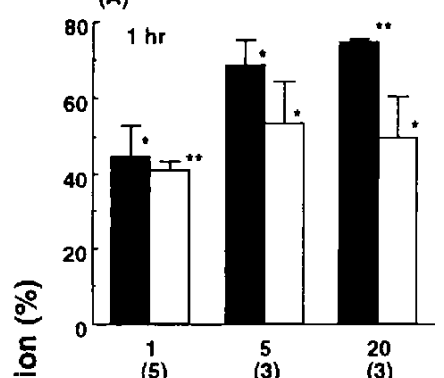

(5)
(B)

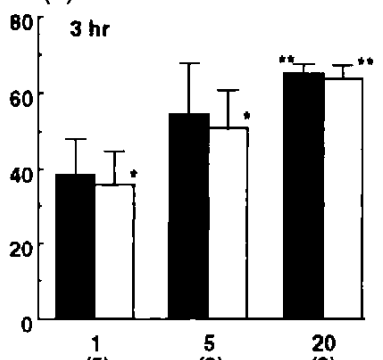

Dose of AL-3264 ( $\mathrm{mg}^{(5)} \mathrm{kg}$, p.o. $)$

(B)

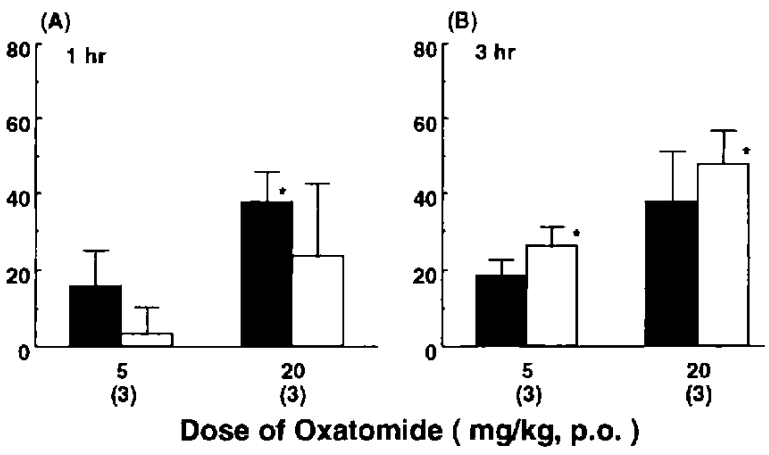

Fig. 1. Effects of AL-3264 and oxatomide on P-K and histamine skin reactions in monkeys. The $P-K$ and histamine skin reactions were caused at $1 \mathrm{hr}(\mathrm{A})$ and $3 \mathrm{hr}(\mathrm{B})$ after drug administration. Each column and bar represents a mean and S.E.M. Closed column: P-K reaction, open column: histamine skin reaction. ${ }^{*} \mathrm{P}<0.05$ and ${ }^{*} \mathrm{P}<0.01$, significantly different from each pre-drug value. ( ): number of monkeys.

hydrochloride (Nacalai Tesque, Kyoto), dust mite antigen (crude extract) and serum of an asthmatic patient who was sensitized with dust mite (Andard-Mount Ltd., London, UK), mepyramine (Sigma, St. Louis, MO, USA) and $\mathrm{LTB}_{4}$ RIA kit (Amersham, Tokyo) were purchased. $N$-[4-[4-(Diphenylmethyl)-1-piperazinyl]butyl]-3-(6-methyl3-pyridyl)acrylamide (AL-3264), oxatomide and ketotifen fumarate were synthesized at Dainippon Pharmaceutical Co., Ltd. The doses of drugs and agents described in this paper refer to the forms presented above.

Statistical significance between groups was analyzed by Student's paired $t$-test.

Figures 1 and 2 show the inhibitory effects of AL-3264, oxatomide, ketotifen and mepyramine on the P-K and histamine skin reactions in monkeys. AL-3264 (1 to 20 $\mathrm{mg} / \mathrm{kg}$, p.o.) dose-relatedly inhibited the P-K and histamine skin reactions at 1 and $3 \mathrm{hr}$ after oral administration. The inhibitory effect of AL-3264 on the P-K reaction was more clearly evident than that on the histamine reaction. Oxatomide ( 5 and $20 \mathrm{mg} / \mathrm{kg}$, p.o.) also inhibited both reactions in a dose-related manner, but its effects were less potent than those of AL-3264. On the contrary, ketotifen $(0.2$ and $1.0 \mathrm{mg} / \mathrm{kg}$, p.o.) and mepyramine ( 5 and $10 \mathrm{mg} / \mathrm{kg}$, p.o.) tended to inhibit the histamine skin

(A)

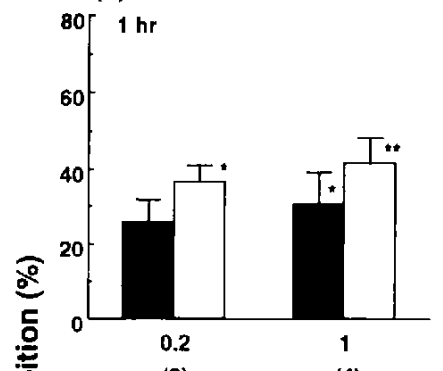

(2)

Dose of Ketotifen ( $\mathrm{mg} / \mathrm{kg}$, p.o.)

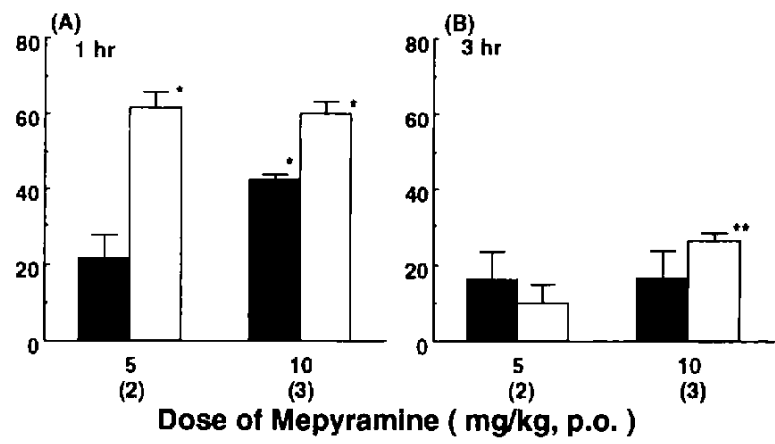

Fig. 2. Effects of ketotifen and mepyramine on P-K and histamine skin reactions in monkeys. The $P-K$ and histamine skin reactions were caused at $1 \mathrm{hr}(\mathrm{A})$ and $3 \mathrm{hr}$ (B) after drug administration. Each column and bar represents a mean and S.E.M. Closed column: P-K reaction, open column: histamine skin reaction. ${ }^{*} \mathrm{P}<0.05$ and ${ }^{*} \mathrm{P}<0.01$, significantly different from each pre-drug value. () : number of monkeys. 


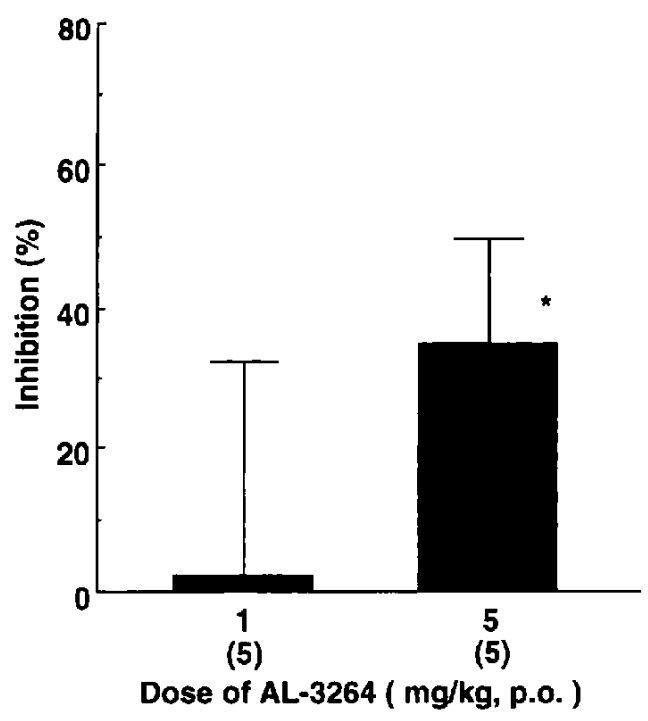

Fig. 3. Effect of AL-3264 on A23,187-induced LTB $_{4}$ production from the broncho-alveolar cells obtained from monkeys. The cells were collected $1 \mathrm{hr}$ after administration of AL-3264 or vehicle. Each column and bar represents a mean and S.E.M. ${ }^{*} \mathbf{P}<0.05$, significantly different from each control value. ( ): number of monkeys.

reaction more clearly than the $\mathrm{P}-\mathrm{K}$ reaction.

As shown in Fig. 3, AL-3264 (5 mg/kg, p.o.) reduced A23,187-induced $\mathrm{LTB}_{4}$ production in isolated bronchoalveolar cells obtained from monkeys at $1 \mathrm{hr}$ after oral administration. The levels of $\mathrm{LTB}_{4}$ in the vehicle control and AL-3264 were $779 \pm 164$ and $762 \pm 235 \mathrm{ng} / 10^{5}$ cells at $1 \mathrm{mg} / \mathrm{kg}$ (inhibitory rate: $2.2 \%$ ) and $757 \pm 107$ and $494 \pm 115 \mathrm{ng} / 10^{5}$ cells at $5 \mathrm{mg} / \mathrm{kg}(34.7 \%, \mathrm{P}<0.05)$, respectively. AL-3264 did not affect the cell population in BALF.

Since histamine and LT, especially $L T$, have been thought to be important mediators of the human allergic reaction, many antiallergic drugs designed to inhibit both mediators have been developed, but not all of them possess sufficient antiallergic effect because of a shortage of inhibitory activity towards LT. To study the balance between the inhibitory effect on LT and the antihistaminic effect, we tried to compare the inhibitory effects of test drugs on the P-K reaction, which was mainly mediated by LT and histamine, similar to the mediation of human allergic diseases (unpublished data, I. Yakuo and $\mathbf{H}$. Nakamura) and on the histamine skin reaction caused simultaneously in the same monkeys. AL-3264 and oxatomide which has multiple actions (8) inhibited the P-K reaction more clearly than the histamine skin reaction at 1 and $3 \mathrm{hr}$ and at $1 \mathrm{hr}$, respectively. On the contrary, both ketotifen, which has extremely potent antihistaminic action (9), and mepyramine, an antihistamine, showed the opposite inhibitory pattern. These results suggest that AL-3264 potently inhibits the $\mathrm{P}-\mathrm{K}$ reaction in monkeys via not only its antihistaminic action but also other actions. The intradermal injection of specific $L T$ antagonists, such as FPL-55712 (20-200 ng/site) and ONO$1078(0.2-20 \mathrm{ng} / \mathrm{site})$, dose-relatedly and potently inhibited the P-K reaction in monkeys (unpublished observation, I. Yakuo and H. Nakamura), supporting the participation of LT in this reaction. So, it is very likely that the inhibition of the LT system is much involved in the mechanism by which AL-3264 inhibits the P-K reaction. Because it has been reported that AL-3264 inhibits 5-LO activity (1) and reduces LT production in rodents (10), we investigated the effect of AL-3264 on the LT production in monkeys. AL-3264 $(5 \mathrm{mg} / \mathrm{kg}$ at which the P-K reaction was inhibited) significantly reduced the A-23,187-induced $\mathrm{LTB}_{4}$ production (inhibitory rate: $34.7 \%$ ). This effect on the LT production may result in the clearer inhibition of the $\mathrm{P}-\mathrm{K}$ reaction than that of the skin reaction evoked by histamine alone.

In conclusion, AL-3264 potently inhibited the P-K reaction in monkeys, which is similar to human allergic diseases. It was suggested that AL-3264 inhibited the P-K reaction via its inhibitory effects on both $\mathrm{LT}$ production and the histamine reaction.

\section{Acknowledgments}

We thank Drs. J. Matsumoto, T. Karasawa and Y. Nishikawa for their helpful advice and drug synthesis and thank Prof. S. Nakajima and Dr. Y. Tohda of Kinki University for technical advice about bronchoalveolar lavage.

\section{REFERENCES}

1 Ishii K, Yakuo I, Seto Y, Kita A, Nakamura H and Nishikawa Y: Antiallergic activity and mode of action of $\mathrm{N}$-[4-[4(diphenylmethyl)-1 -piperazinyl]butyl]-3-(6-methyl-3-pyridyl)acrylamide in experimental animals. Arzneimittelforschung 43 , $148-154$ (1993)

2 Ishii K, Yakuo I, Nakagawa $\mathrm{H}$ and Nakamura H: Dissociation between central and peripheral antihistamine activities of the new antiallergic agent $N$-[4-[4-(diphenylmethyl)-1-piperazinyl]butyl]-3-(6-methyl-3-pyridyl)acrylamide in rats and monkeys. Arzneimittelforschung 43, 668-671 (1993)

3 Weiszer I, Patterson R and Pruzansky JJ: Ascaris hypersensitivity in the rhesus monkey; I. A model for the study of immediate type hypersensitivity in the primate. J Allergy 41, 14-22 (1958)

4 Patterson R, Talbot $\mathrm{CH}$ and Brandfonbrener $\mathrm{M}$ : The use of $\operatorname{IgE}$ mediated responses as a pharmacologic test system; The effect of disodium cromoglycate in respiratory and cutaneous reactions and on the electrocardiograms of rhesus monkeys. Int Arch Allergy 41, 592-603 (1971)

5 Chiba N, Tamura T, Koizumi $\mathrm{K}$, Tanigawa $\mathbf{M}$ and Shiba $\mathrm{M}$ : Experimental cedar pollinosis in rhesus monkeys. Int Arch Allergy Appl Immunol 93, 83-88 (1990)

6 Patterson R, Fink JN, Nishimura ET and Pruzansky JJ: The passive transfer of immediate type hypersensitivity from man to other primates. J Clin Invest 44, 140-148 (1965)

7 Ishizaka K, Ishizaka T and Arbesman CE: Induction of passive 
cutaneous anaphylaxis in monkeys by human $\mathrm{rE}$ antibody. J Allergy 39, 254-264 (1967)

8 Richards DM, Brogden RN, Heel RC, Speight TM and Avery GS: Oxatomide, a review of its pharmacodynamic properties and therapeutic efficacy. Drugs 27, 210-231 (1984)

9 Martin U and Romer D: The pharmacological properties of a new, orally active antianaphylactic compound: ketotifen, a benzocycloheptathiophene. Arzneimittelforschung 28, 770-782 (1978)

10 Ishii K, Yakuo I, Motoyoshi S, Nakagawa $H$ and Nakamura $H$ : Inhibition of leukotriene production by $N$-[4-[4-(diphenylmethyl)-1-piperazinyl]butyl)-3-(6-methyl-3-pyridyl)acrylamide (AL-3264), a new antiallergic agent. Jpn J Pharmacol 65, $19-25(1994)$ 